\title{
Cooperative Learning in Veterinary Science
}

Chicharro-Alcántara, Déborah ${ }^{1}$, Damiá-Giménez, Elena ${ }^{1}$, Cuervo-Serrato, Belén ${ }^{1}$, Rubio-Zaragoza, Mónica ${ }^{1}$, Carrillo-Poveda, José M. ${ }^{1}$, Sopena-Juncosa, Joaquín J. ${ }^{1}$, Jaber-Mohamand, José R. ${ }^{2}$, Vilar-Guereño, José M. ${ }^{2}$

${ }^{1}$ Departamento de Medicina y Cirugía Animal. Facultad de Veterinaria Tirant lo Blanch, 46115, Alfara del Patriarca, Universidad Cardenal Herrera-CEU, CEU Universities, Valencia, Spain

${ }^{2}$ Instituto Universitario de Investigaciones Biomédicas y Sanitarias. Departamento de Patologia Animal. Universidad de Las Palmas de Gran Canaria. 35416. Trasmontaña S/N. Arucas, Spain

Corresponding author: Joaquín J. Sopena-Juncosa

\begin{abstract}
Cooperative learning is an instructional method based on teamwork, by reinforcing a student's own learning as well as the learning of his or her fellow members. Thus, this kind of cooperative model achieves personal and team success at the same time. With this aim, an experience was designed where students from veterinary surgery and propaedeutics from the Universities of Las Palmas de Gran Canaria (ULPGC) and CEU Cardenal Herrera of Valencia (UCH-CEU) simultaneously performed surgical practices in the Veterinary Medicine Degree. Propaedeutic students were evaluated previously and after the practical period with surgery multiplechoice questions and results were compared. The obtained results allow us to conclude that students after interaction gained advanced knowledge in veterinary surgery.
\end{abstract}

Indexing terms/Keywords: Cooperative Learning, Interaction, Veterinary, Surgery, Propaedeutics.

Subject Classification: KA 903. Communication, Education, And Information Delivery

Type (Method/Approach): science of teaching, learning, and cognition

Date of Publication: 2018-08-30

DOI: https://doi.org/10.24297/jaa.v8i1.7543

ISSN: 2349-0837

Volume: 08 Issue: 01

Journal: Journal of Advances in Agriculture

Publisher: CIRWORLD

Website: https://cirworld.com

This work is licensed under a Creative Commons Attribution 4.0 International License. 


\section{Introduction}

Kagan \& Kagan [1] describe cooperative learning $(\mathrm{CL})$ as "a series of instructional strategies that include student-student cooperative interaction. In simpler words, Johnson \& Johnson [2] define $\mathrm{CL}$ as "the instructional use of small groups to promote students working together to maximize their own and each other's learning". It is characterized by positive interdependence, where students notice that better performance by individuals generates better performance by the entire group [3]. In addition, CL can be adapted to work with small and large classes and across disciplines, and can be formal or informal, although it often involves the intervention of instructors to maximize student interaction and learning [3].

Several requirements or elements are needed to make this model productive: 1) the positive interdependence, where everyone's effort is needed, 2) mutual support in face-to-face interactions, where students share questions, materials, information, within others. 3) individual personal responsability, where each student must explain the work done to the rest of the group 4) interpersonal and social skills, to establish confidence and communication in between the group members and 5) frequent self-assessment of group functioning.

The use of $\mathrm{CL}$ in teaching is based on the principle of constructivism that rests on the idea that students learn by building their own knowledge, connecting new ideas to existing knowledge to form new or enhanced understanding [4]. The relationship between cognitive processes and social activities was evaluated by Lev Vygotsky, by developing the sociocultural theory of development. The mentioned theory suggested that learning takes place when students solve problems beyond their current developmental level thanks to the support from their instructor and peers.

Regarding the different cooperative working models the peer tutoring highlights, which consists of matching students with different knowledge levels and competences to achieve a shared and specific purpose. It is an unequal relationship where one of the students acts as the tutor and the other, as the tutored student [2].

According to Elisabeth Coello [5], this allows every member in the group to share the same aims and enables the development of a shared identity and the same purpose. In addition, it favors the positive interpersonal relationship. Moreover, Panitz [6] states that $\mathrm{CL}$ promotes students metacognition and allows them to feel the control over their tasks (academic benefits); $C L$ also stimulates students to see situations from different perspectives and creates an environment where they can practice leadership skills (social benefits). Finally, enhances student's satisfaction with the learning experience and decreases significantly student's anxiety (psychological benefits).

Our hypothesis is that $\mathrm{CL}$ could be useful in the acquisition of skills and knowledge in students without previous formation in veterinary surgery.

Based on the previous statements, the aim of our study is to evaluate if $\mathrm{CL}$ is useful for knowledge acquisition in students which have not received formal training in surgery subject at the Veterinary Medicine Degree.

\section{Materials and Methods}

To design this $\mathrm{CL}$ experience, 25 students from veterinary propaedeutics were used, 13 of these came from ULPGC and the remaining 12 from UCH-CEU Valencia. None of these students had previously been involved in subjects related to surgery. A multiple-choice test which included general surgical concepts was designed and handed out to the mentioned propaedeutics students to evaluate their knowledge in surgery, under the condition of just answering those questions they knew.

Multiple choice questions were the following:

1) The linea alba or white line is:

A. A fibrous band that joins muscles from both sides of the neck 
B. A structure found in the retina

C. A fibrous band that joins muscles from both sides of the abdomen

D. Does not exist

2) To identify the uterus, we use as anatomical reference:

A. The urinary bladder

B. The colon

C. The stomach

D. The spleen

3) The appropriate disinfection of the surgical site is:

A. The use three different antiseptics

B. The use of two antiseptics, three times each, alternately

C. The use of one antiseptic two times

D. The use of one antiseptic three times

4) Prior to section, an important artery must be ligated at least:
A. Once
B. Twice
C. Three times
D. Four times

5) What type of sutures are commonly used internally in an animal?
A. Absorbent
B. Non-absorbent
C. Absorbable
D. Non-absorbable

6) Why do we cover abdominal organs with the omentum before closing the abdominal cavity?

A. Because they were already covered before surgery

B. To prevent adhesions

C. Because it improves aethetics

D. Abdominal organs should not be covered by omentum 
7) Do you feel fully trained to suture a wound?
A. Yes
B. No
8) Isoflurane is:
A. An antibiotic

B. An anti-inflammatory

C. An anesthetic gas

D. An anesthetic injection

9) Handling of surgical scissors: (fingers)
A. Index and thumb
B. Thumb and middle finger
C. Thumb and ring finger
D. Thumb and pinky finger (Fig 2)

10) Anesthetic premedication is used to:
A. Decrease the amount of general anesthetic agents and their undesirable effects
B. Save anesthetic agents which are very expensive
C. Premedication includes general anesthesia
D. Avoid prescribing antibiotics after surgery (Fig 3)

11) A prescrotal incision is used to:
A. Amputate the penis
B. There is no surgical technique involving this incision
C. Castrate a male dog
D. Castrate a male cat

12) The antidote of dexmedetomidine (Dexdomitor $\left.{ }^{\circledR}\right)$ is:
A. Atipamezole "Antisedan ${ }^{\circledR}$
B. Despertol
C. Romifidine
D. Ketamine 
13) Atipamezole in cats is used at the following dose:
A. Same as dexdomitor ${ }^{\circledR}$
B. Double to dexdomitor ${ }^{\circledR}$
C. One fourth part of dexdomitor ${ }^{\circledR}$
D. Half to dexdomitor ${ }^{\circledR}$

Subsequently, students are placed together during 5 days to carry out their clinical practical training with students from surgery (Figure 1).

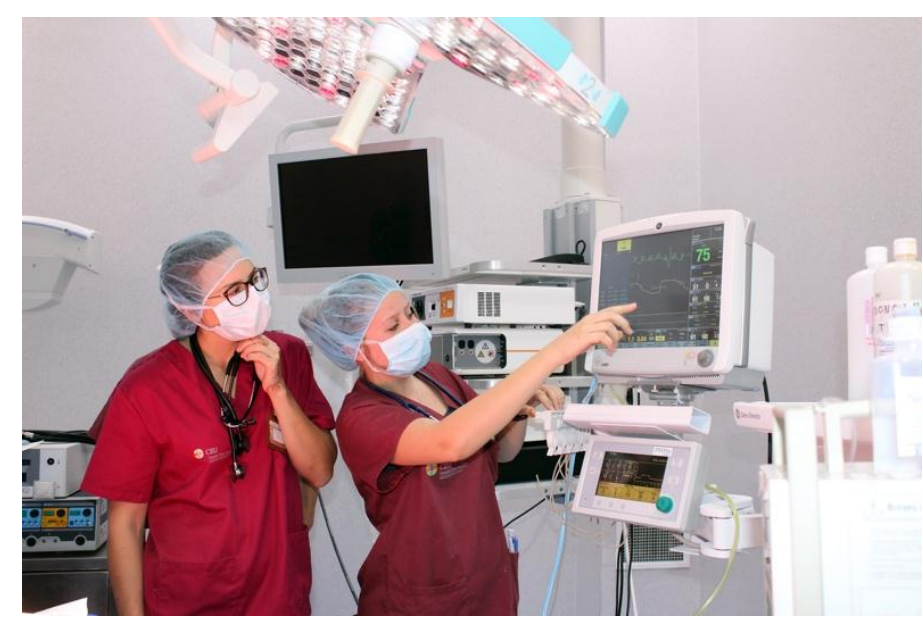

Figure 1: Learning how to perform the patient monitoring during a surgical intervention.

During these practical classes, surgery students apply their theoretical knowledge regarding pre-operative preparation and surgical procedures on patients (Figure 2).

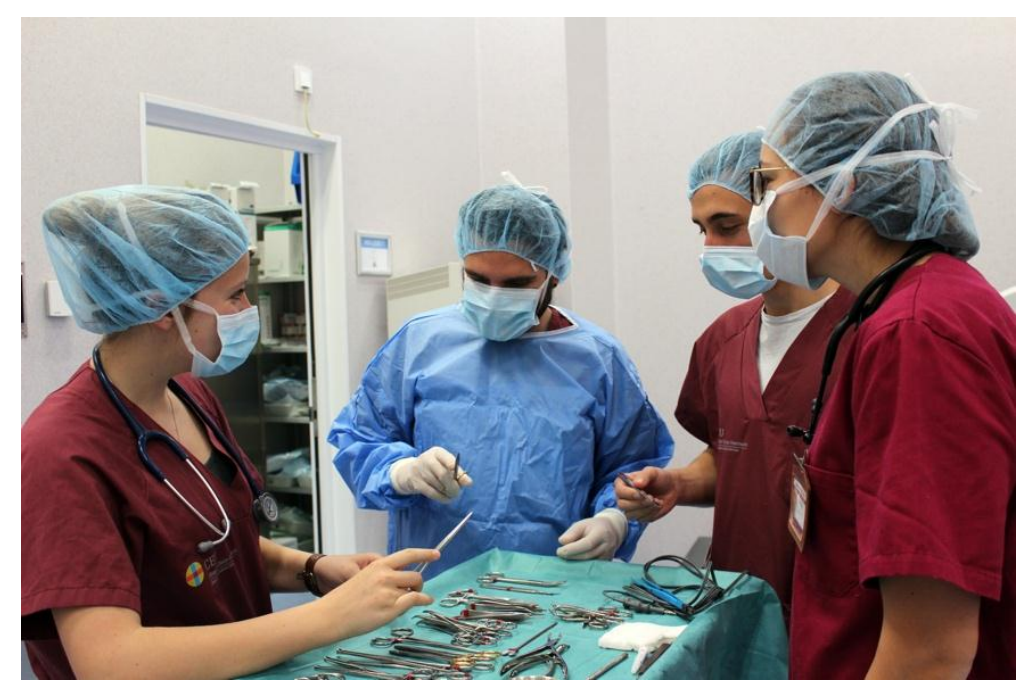

Figure 2: Knowledge of the surgical instrumentation and how to use them properly. 
At the same time, lecturers took special care to avoid using any knowledge which would subsequently be used to evaluate propaedeutic students, but instead their doubts would be directly solved by their tutor-student

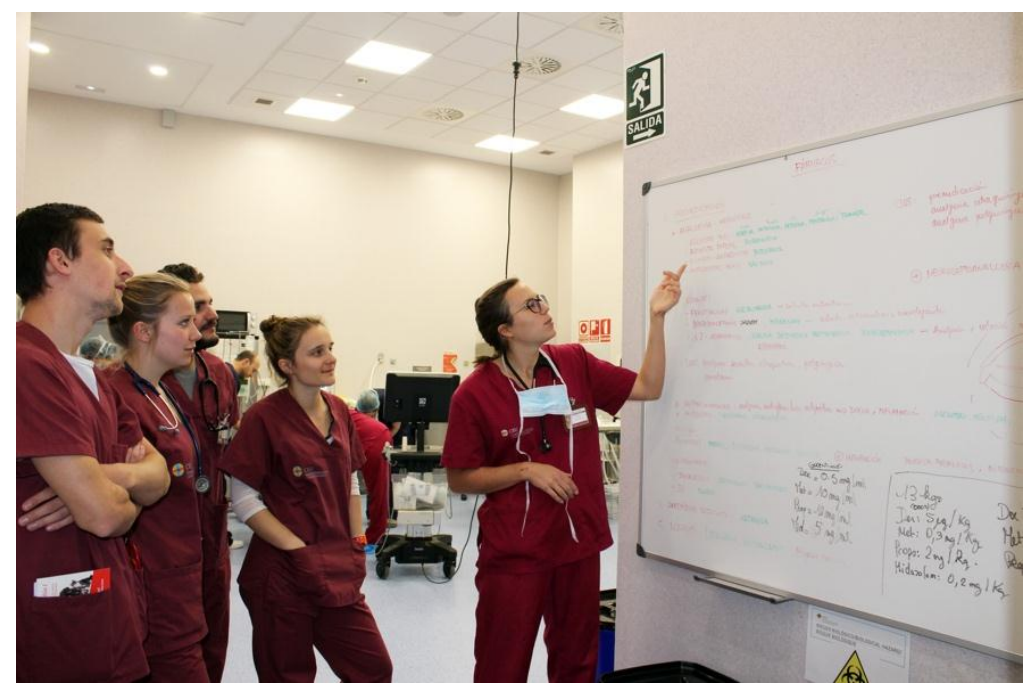

(peer tutoring) (Figure 3).

Figure 3: Learning anesthetic and preanesthetic drugs and combinations.

After the practical training period, the same multiple choice test was done once again, and previous and subsequent results to the practical class were statistically compared.

\section{Results and Discussion}

Results are summarized in the following table:

\begin{tabular}{|l|l|l|l|l|l|l|}
\cline { 2 - 7 } \multicolumn{1}{l|}{} & Before practical & \multicolumn{2}{l|}{ After practical } \\
\hline $\begin{array}{l}N^{\circ} \\
\text { Questions }\end{array}$ & Correct & Incorrect & NA & Correct & Incorrect & NA \\
\hline 1 & 17 & 2 & 6 & 25 & 0 & 0 \\
\hline 2 & 6 & 2 & 17 & 18 & 3 & 4 \\
\hline 3 & 4 & 12 & 9 & 17 & 5 & 3 \\
\hline 4 & 6 & 10 & 9 & 11 & 9 & 5 \\
\hline 5 & 11 & 7 & 7 & 15 & 5 & 5 \\
\hline 6 & 5 & 6 & 14 & 13 & 4 & 8 \\
\hline 7 & 4 & 21 & 0 & 9 & 15 & 1 \\
\hline 8 & 7 & 3 & 15 & 17 & 2 & 6 \\
\hline 9 & 4 & 14 & 7 & 16 & 8 & 1 \\
\hline 10 & 10 & 5 & 10 & 18 & 3 & 4 \\
\hline 11 & 6 & 5 & 14 & 14 & 3 & 8 \\
\hline 12 & 5 & 1 & 19 & 8 & 1 & 16 \\
\hline 13 & 3 & 1 & 21 & 5 & 3 & 17 \\
\hline
\end{tabular}

$N^{\circ}$ : Number, NA: No answer

Table 1: Individual results for each question, before and after carrying out the practical activity on $\mathrm{CL}$. 
The percentage of correct answers in the "After practical" group was $57,23 \%$ Vs $27,07 \%$, the percentage of incorrect answers was $18,76 \%$ Vs $27,38 \%$, and the NA 24 Vs $45,43 \%$, respectively. From these data we can clearly appreciate a huge difference (around twice more) of students that after the $\mathrm{CL}$ experience anwer questions correctly; this difference is half of the students that think they don't know the answers and therefore choose not to answer.

Cooperative learning has been included in several subjects from the Veterinary Medicine Degree for many years, having proved their efficacy, especially when they are done using real clinical cases [7]. In agreement with these authors, and taking into account the results, our students showed great interest in understanding the basic needed knowledge to address, understand and help during the preparation and surgical procedure of real patients with pathologies or surgical requirements.

To allow a correct development of the $C L$ experience, the surgery students (which acted as tutors) received previous instructions regarding their roles and responsibilities over their classmates training, which is important to achieve reciprocal learning [8].

As mentioned previously, placing students in groups and expecting them to work together will not necessarily promote cooperation [9]. Groups need to be established so that the five key components of successful $\mathrm{CL}$ are embedded in their structure [10]. The first key component involves structuring a positive interdependencelearning situation; to do so, students must understand that they are each responsible for completing a part of the task. Teachers can ensure this happens by assigning different parts of the group's task to individual group members [11].

To promote interaction is the second key component. Willingness to engage with others not only benefits recipients but also helpers because giving help encourages helpers to reorganize and restructure information in their own minds, and this promotes cognitive understandings [12]. Interaction in groups can be facilitated by teachers sitting students in close proximity to other group members [13].

The third key component is one's responsibility in ensuring that the student completes their part of the work while also ensuring that others complete theirs [9]. Teachers can establish individual accountability by either structuring positive interdependence in between group members or by making students personally responsible for completing their part of the task [2].

The need of interpersonal skills is the fourth key component to manage disagreements between group members. Student must be taught the social skills needed for high quality cooperation and must be motivated to use them to facilitate learning of themselves and others [10].

The final key component for successful $\mathrm{CL}$ is group processing, where students reflect their progress and working relationships [9]. In a study carried out by Johnson et al [14] they found that students had a higher achievement gains when they participated in group processing discussions in comparison to students that did not undergo these experiences.

One of the main obstacles that could be present in this type of learning, and create concern for students acting as "tutors" is that with the absence of a direct supervision from teachers, students would show up less collaborative. However, in our study it happened all the opposite, since the pressure and stress they feel when being observed and judged disappears; it thus stimulates them to participate more and be less afraid to make mistakes. The previously mentioned information has been partially described by other authors [15]. 
In agreement with our results, a group of researchers performed a meta-analysis of 168 studies where they compared cooperative learning to competitive learning and individualistic learning in college students [16] and found a significant greater academic achievement with cooperative learning compared to competitive and individualistic learning. In addition, others authors concluded that $\mathrm{CL}$ enhances student engagement and academic performance [17]. Furthermore, Springer et al [18] observed once more that students participating in several types of small-group learning showed a greater academic achievement with more positive attitudes rewards learning compared to students who did not participate in small-group learning.

Finally, one of the main advantages of this system, in which students gain knowledge previously to the development of a subject (in this case veterinary surgery) is the fact that it stimulates students to participate during class and encourages them to ask more relevant questions [8].

\section{Conclusions}

Our results show a meaningful increase in the benefits of knowledge acquisition for students using $\mathrm{CL}$, supporting positive group interdependence and creating a social environment where students learn through interaction and communication among group members.

\section{Data Availability (excluding Review articles)}

Data are available in the archives of the authors.

\section{Conflicts of Interest}

Authors have no conflicts of interest to disclose

\section{Funding Statement}

The authors received no direct funding for this research. This research was performed as part of the employment of the authors: Universidad Cardenal Herrera-CEU, CEU Universities, Valencia, Spain and Universidad de Las Palmas de Gran Canaria, Spain.

\section{Acknowledgments}

The authors gratefully acknowledge to the students for their cooperation in the study.

\section{References}

1. Kagan S, K. M., Kagan Cooperative Learning. Kagan Publishing: San Clemente, 1994.

2. Johnson, D. W., Johnson, RT, Cooperative learning and achievement. In Cooperative learning: theory and reseach, Sharan, S., Ed. Praeger: New York, 1990; pp 23-27.

3. Johnson, D. W., Johnson, R.T., and Smith, K.A. , Cooperative learning: Improving university instruction by basing practice on validated theory. J Excell in Coll Teach 2014, 25, 85-118.

4. Bransford, J. D., Brown, A.L., and Cocking, R.R, How people learn: Brain, mind, experience, and school. National Academy Press: Washington, D.C, 1999.

5. Coelho, E., Teaching and learning in multicultural schools. An integrated approach. Multilingual Matters: England, 1998.

6. Panitz, T. The case for student centered instruction via collaborative learning pardigms; 2004.

7. Haynes J, M. R., A Case-Based, Cooperative Leaming Approach to Teaching Veterinary Systemic Pathology. J Vet Med Educ 1999, 25, 12-16. 
8. Monahan $\mathrm{CM}, \mathrm{Y}$. A., Adapting a case-based, cooperative learning strategy to a veterinary parasitology laboratory. J Vet Med Educ 2002, 29, 186-192.

9. Gillies, R. M., Cooperative learning: Review of research and practice. Australian J of teacher education 2016, $41,(3), 39-54$

10. Johnson, D., Johnson, F, Joining together: Group theory and group skills Pearson education: Upper saddle river, New Jersey, 2009.

11. Johnson, D., \& Johnson RT, Learning together and alone: Overview and meta-analysis. Asia Pac J Educ 2002, 22, 95-105.

12. Webb, N., Task-related verbal interaction and mathematics learning in small groups. J Res Mathem Educ 1991, 22, 366-389.

13. Gillies, R. M., Structuring cooperative group work in classrooms. Int J Educ Res 2003, 39, 35-49.

14. Johnson, D., Johnson, RT., Stanne, M., and Giribaldi, A, Impact of group processing on achievement in cooperative groups. J Soc Psychol 1990, 130, 507-516.

15. Dale V, N. L., Sullivan M, Evaluation of Student Attitudes to Cooperative Learning in Undergraduate Veterinary Medicine. J Vet Med Educ 2005, 32, 511-516.

16. Johnson, D. W., Johnson, R.T., and Smith, K.A, Active learning: Cooperation in the university classroom. Edina, MN: Interaction: Minnesota, 2006.

17. Kuh, G. D., Kinzie, J., Buckley, J., Bridges, B., and Hayek, J.C. Piecing together the student success puzzle: Research, propositions, and recommendations; 2007; pp 1-182.

18. Springer, L., Stanne, M. E., \& Donovan, S. S. , Effects of small-group learning on undergraduates in science, mathematics, engineering, and technology: A meta-analysis. Rev Educ Res 1999, 96, (1), 21-51. 